\title{
Mechanical Properties of Friction-Stir-Welded Inconel 625 Alloy
}

\author{
Kuk Hyun Song* and Kazuhiro Nakata \\ Joining and Welding Research Institute, Osaka University, Ibaraki 567-0047, Japan
}

\begin{abstract}
The present study was carried out to evaluate the microstructural and mechanical properties on friction stir welded Inconel 625 alloy. For this work, friction stir welding was performed at a tool rotation speed of $200 \mathrm{rpm}$ and a traveling speed of $100 \mathrm{~mm} / \mathrm{min}$. As a result, the grain refinement was achieved from $10.3 \mu \mathrm{m}$ in the base material to $2.1 \mu \mathrm{m}$ in the stir zone at an average grain size, accompanied by the dynamic recrystallization. This grain refinement has an effect on the increase of mechanical properties so that microhardness and tensile strength were significantly increased than that of the base material, more than 40\% and 15\% in fraction, respectively. [doi:10.2320/matertrans.M2009200]
\end{abstract}

(Received June 11, 2009; Accepted July 23, 2009; Published September 9, 2009)

Keywords: Inconel 625, friction stir welding, mechanical properties

\section{Introduction}

Inconel 625 alloy is widely used in aerospace systems, chemical power plants, and marine systems due to its properties such as high tensile strength, high corrosion resistance, and excellent fabricability. ${ }^{1)}$ Furthermore, as it is a solid solution strengthened material by molybdenum and niobium on its nickel-chromium matrix, the high strength can be retained without any precipitation heat-treatment. ${ }^{1)}$ In addition, it exhibits precipitation hardening at elevated temperatures for precipitates such as $\gamma^{\prime}, \gamma^{\prime \prime}$, and MC carbides $\left(\mathrm{MC}, \mathrm{M}_{6} \mathrm{C}\right.$, and $\mathrm{M}_{23} \mathrm{C}_{6}$ ). ${ }^{2,3)}$ Generally, for the construction of chemical power plants and repairing of power generator parts, where Ni-based alloys are used, fusion-welding methods such as gas tungsten arc welding (GTAW) and laser welding are used. ${ }^{4,5)}$ However, in these fusion welds, because of the formation of a cast structure, it is difficult to obtain excellent physical and chemical properties of the weld zone. ${ }^{4,5)}$ Therefore, an alternative welding method, friction stir welding (FSW), by which a material is maintained in the solid state due to its lower heat input, is proposed in this study.

Friction stir welding (FSW) has several advantages over fusion welding methods; one such advantage is defect suppression; for example, blow holes, hot cracking, and segregation do not occur in FSW. ${ }^{6,7)}$ In particular, the FSW of materials with lower melting points, such as $\mathrm{Mg}$ and $\mathrm{Al}$ alloys, has been carried out often. ${ }^{8-10)}$ However, the FSW of Ni-based super-alloys has been rarely carried out because of their high strength even at high temperatures. Only Inconel 600 has been reported to be friction stir welded; albeit, at a lower welding speed. ${ }^{11,12)}$ Furthermore, the FSW of Inconel 625 , which has higher tensile strength than Inconel 600, has not been previously reported. Therefore, this study was conducted to evaluate the possibility of FSW of Inconel 625 and examine the microstructure and mechanical properties of the weld zone.

\section{Experimental Procedures}

The material used in this study was an Inconel 625 sheet with a size of $65 \mathrm{~mm} \times 150 \mathrm{~mm} \times 2 \mathrm{~mm}$; its chemical

*Corresponding author, E-mail: song@jwri.osaka-u.ac.jp composition in mass $\%$ was as follows: Cr: $21.99 \%$, Fe: $3.24 \%$, Mo: $9.00 \%$, Nb: 3.53\%, C: $0.01 \%$, Mn: 0.10\%, Si: $0.09 \%, \mathrm{~S}: 0.001 \%, \mathrm{Al}: 0.18 \%$, Ti: $0.32 \%$ and Ni-balance. FSW was carried out at a tool rotation speed of $200 \mathrm{rpm}$ and a traveling speed of $100 \mathrm{~mm} / \mathrm{min}$ using a tungsten carbidecobalt (WC-Co) tool with a shoulder diameter of $15 \mathrm{~mm}$ and a probe with diameter and length of $6 \mathrm{~mm}$ and $1.8 \mathrm{~mm}$, respectively. In order to achieve good weld quality, the tool was tilted forward by $3^{\circ}$ from the vertical, and argon gas was used to prevent surface oxidation during welding. To observe the macrostructures and microstructures of the welded materials, a solution consisting of $15 \mathrm{ml} \mathrm{HCl}, 10 \mathrm{ml}$ $\mathrm{CH}_{3} \mathrm{COOH}_{3}$, and $5 \mathrm{ml} \mathrm{HNO}$ was prepared. The surfaces of the samples were etched with this solution after polishing them with abrasive paper. Furthermore, microhardness and tensile tests were carried out in order to investigate the mechanical properties of the alloy. The Vickers hardness test was carried out along the cross section of the weld zone using a load of $9.8 \mathrm{~N}$ and a dwell time of $15 \mathrm{~s}$. Two types of specimens were used in the tensile tests for evaluating the transverse tensile strength of the welds and longitudinal tensile strength of the stir zone.

\section{Results and Discussion}

The macrostructure of friction-stir-welded Inconel 625 is shown in Fig. 1. The weld penetrated to a depth of $1.7 \mathrm{~mm}$ into the specimen without introducing any defects; however, a band structure was observed at the center of the stir zone. Results of scanning electron microscopy (SEM) and energy dispersive spectroscopy (EDS) analyses of the band structure and normal stir zone are shown in Fig. 2. As shown in Fig. 2(b), it can be observed that tungsten (W) from the tool was detected in the band structure; however, it was not detected in the normal stir zone. A similar result was previously obtained in a research conducted on materials with a high melting point. ${ }^{12)}$ Therefore, it is considered that the band structure occurred by tool wear due to its higher friction load between material and tool during FSW.

The temperature distribution during FSW is shown in Fig. 3. It was measured on the back side of the plate at the center of the stir zone. The maximum temperature in the stir zone was found to be approximately $800^{\circ} \mathrm{C}$, which was sufficient to recrystallize the grains of Inconel 625 . Because 


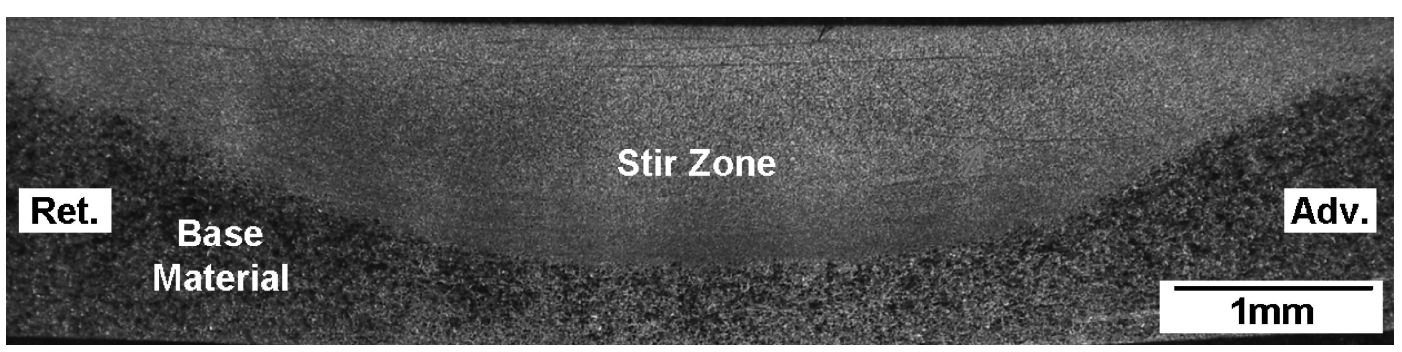

Fig. 1 Macrostructure of weld zone in friction stir welded Inconel 625. Adv. and Ret. indicate the advancing side and retreating side, respectively, of the weld. Arrows indicate the band structure in the stir zone.

(a)

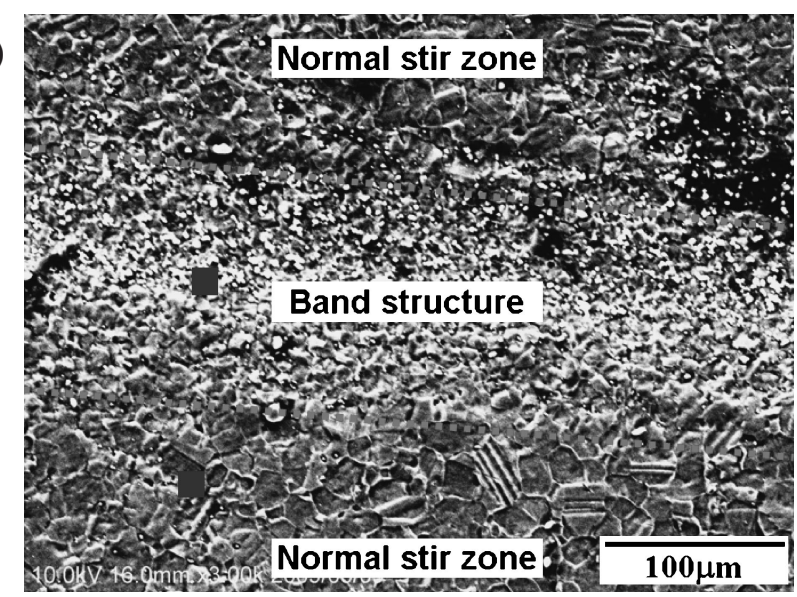

(b)

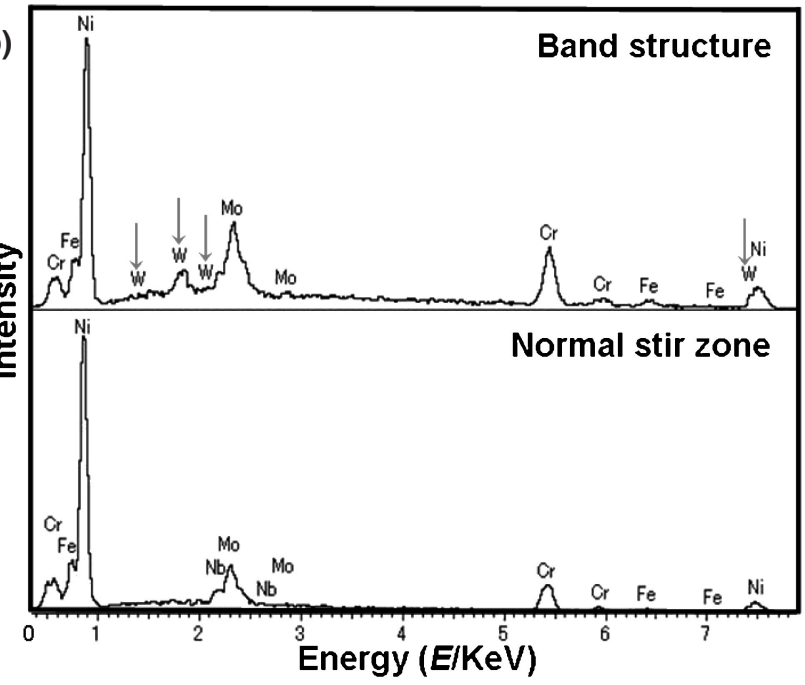

Fig. 2 (a) SEM image and (b) EDS spectra obtained from band structure.

the temperature distribution measurement was carried out at the bottom of the specimen, it is considered that the maximum temperature in the stir zone could be higher than that at the center of the stir zone. Therefore, it is believed that Inconel 625 is well recrystallized during FSW.

The results of SEM and EDS analyses of the base material and stir zone are shown in Fig. 4. The grain diameter of the base material was found to be in the range of $5 \mu \mathrm{m}$ to $15 \mu \mathrm{m}$, with an average diameter of $10.3 \mu \mathrm{m}$, as shown in Fig. 4(a). In addition, $\mathrm{MC}$ carbides such as $\mathrm{NbC}$ and $(\mathrm{Ti}, \mathrm{Nb}) \mathrm{C}$ were distributed in the grains and grain boundaries. In the case of the welded material, the stir zone comprised more refined grains in comparison with that of the base material, with the grain diameter ranging between $1.5 \mu \mathrm{m}$ and $3 \mu \mathrm{m}$ with an

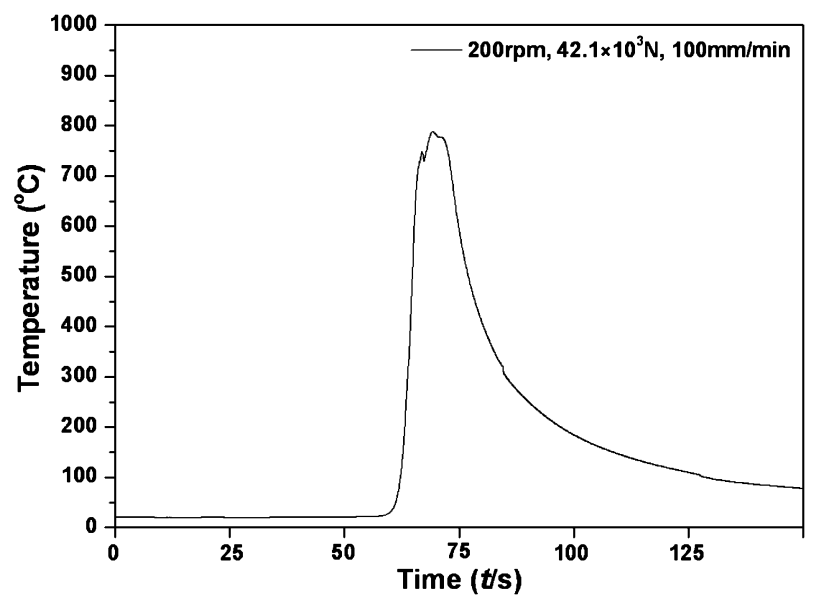

Fig. 3 Temperature hysteresis in stir zone during friction stir welding.

average diameter of $2.1 \mu \mathrm{m}$, as shown in Fig. 4(b). MC carbides similar to those in the base material were distributed in the welded material.

Grain refinement by FSW can be explained in terms of dynamic recrystallization, which occurred due to plastic flow and friction heat. In other words, the stored energy due to the plastic flow can be higher during FSW, accompanied with an enough heat to be recrystallized. Also, Inconel 625 is the material with low stacking fault energy of the F.C.C. metals, which is easy to be recrystallized during the hot working when compared to the material with higher stacking fault energy. ${ }^{13,14)}$ Therefore, FSW is effective in the grain refinement of Inconel 625.

The microhardness distribution of the weld material is shown in Fig. 5. The microhardness of the base material and stir zone ranges between $245 \sim 270 \mathrm{Hv}$ and $360 \sim 400 \mathrm{Hv}$, respectively. The increase in the microhardness of the stir zone is mainly due to grain refinement, where the distribution of refined grains is greater than that in the base material.

Top views of the specimens used in the tensile test are shown in Fig. 6. The base material elongated uniformly and broke at its center, as shown in Fig. 6(a). However, the FSW joint elongated preferentially at the base material and fractured without deformation of the stir zone, as shown in Fig. 6(b). In contrast, the FSW stir zone specimen elongated uniformly at the base material and broke at its center, as shown in Fig. 6(c). The results of the tensile test are shown in Fig. 7. The base material had an ultimate tensile strength (UTS) of $943 \mathrm{MPa}$ with an elongation of 58\%. However, the FSW joint and FSW stir zone specimens had UTS values of 
(a)
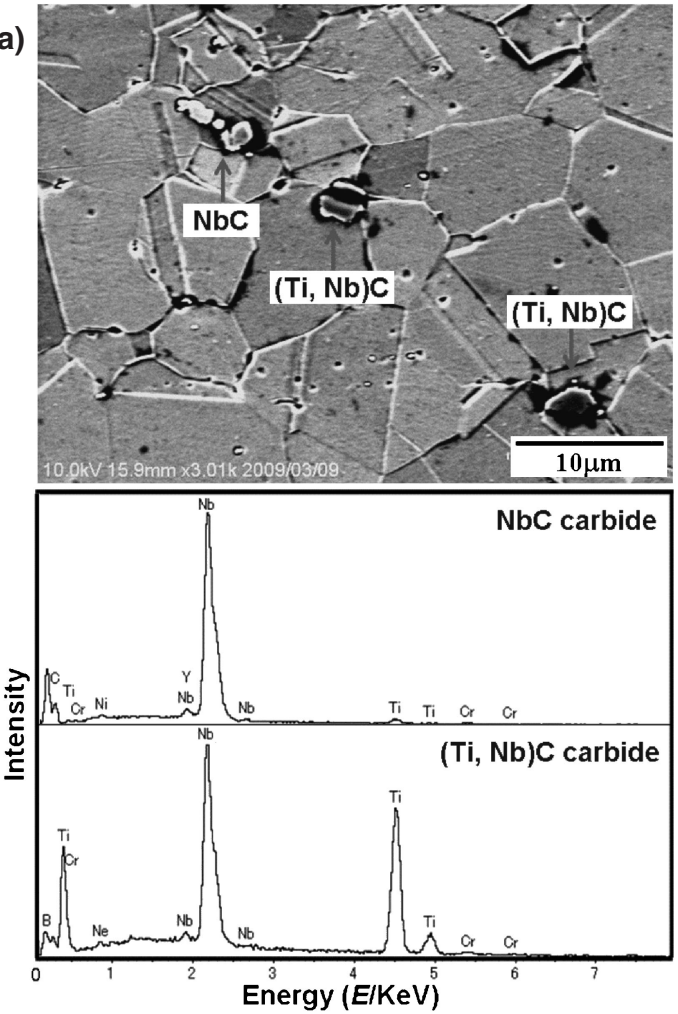

(b)
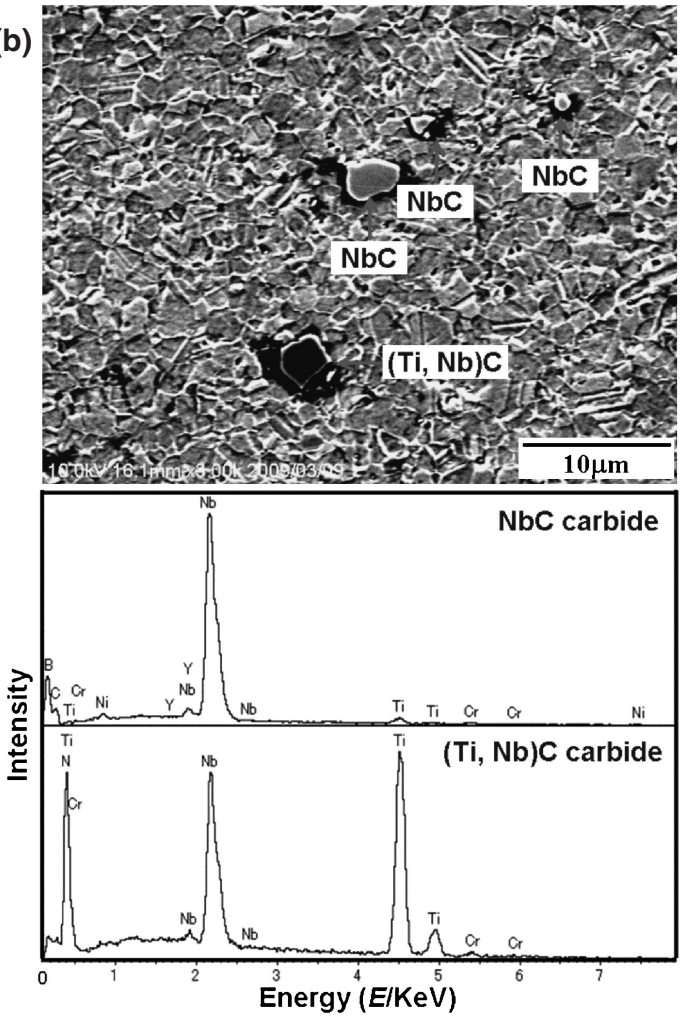

Fig. 4 SEM image and EDS spectra obtained from (a) base material and (b) stir zone.

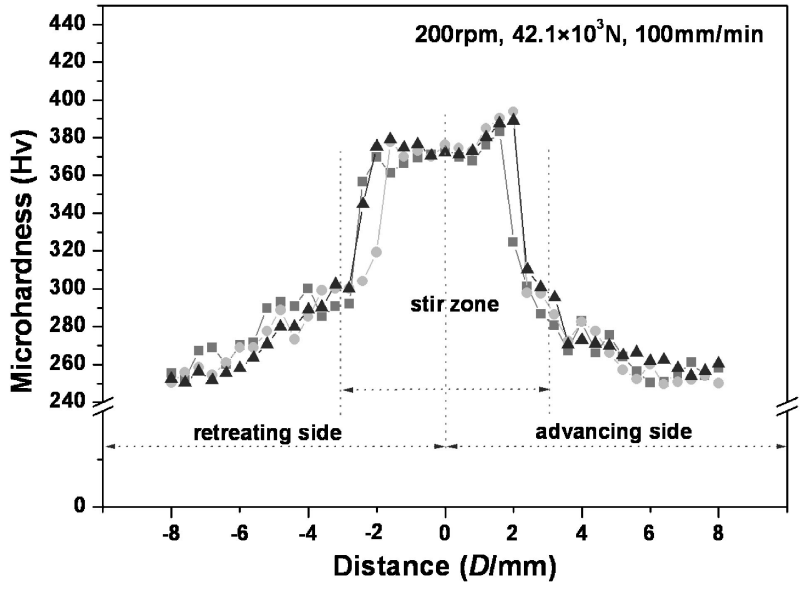

Fig. 5 Vickers microhardness distribution in friction-stir-welded Inconel 625. The Vickers hardness test was carried out three times along the cross section on the center of the specimen.

$1019 \mathrm{MPa}$ and $1152 \mathrm{MPa}$, with elongations of $34 \%$ and $35 \%$, respectively. These results imply that FSW resulted in an increase in the strength of the alloy due to grain refinement in the stir zone.

\section{Conclusions}

In this study, Inconel 625, which is a solid solution strengthened material because of the presence of $\mathrm{Mo}$ and $\mathrm{Nb}$, was successfully welded using the FSW technique without the formation of any weld defects. In addition, FSW resulted in the grain refinement of the alloy accompanied by an enhancement in its mechanical properties. In particular, the
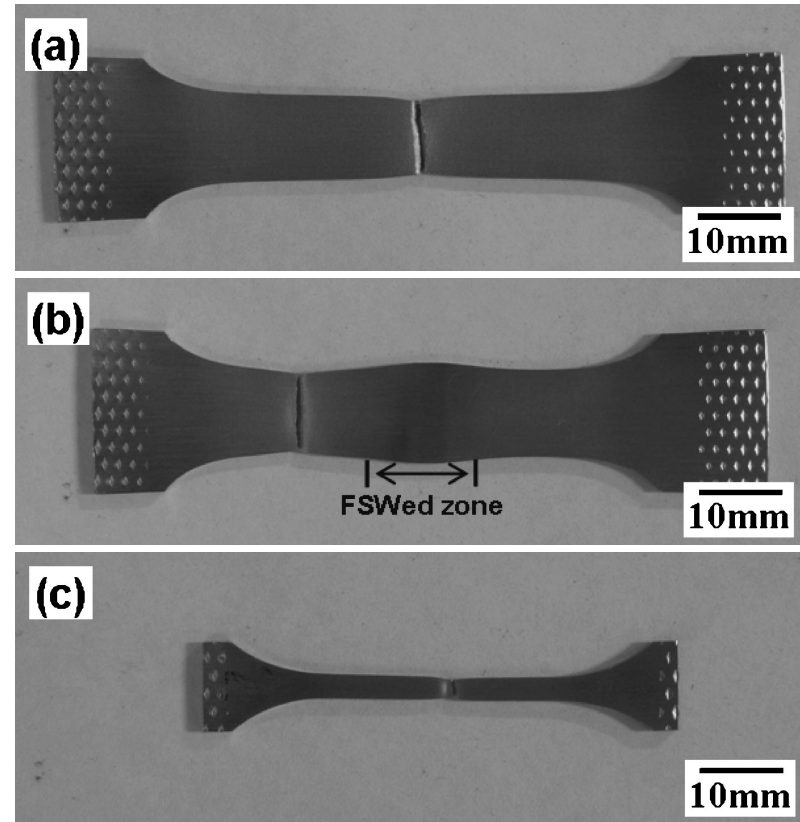

Fig. 6 Top views of specimens subjected to tensile tests. Transverse directions: (a) base material and (b) specimen welded at welding speed of $100 \mathrm{~mm} / \mathrm{min}$. Longitudinal direction: (c) specimen welded at welding speed of $100 \mathrm{~mm} / \mathrm{min}$.

UTS of the FSW stir zone specimen was improved by more than $20 \%$ as compared to that of the base material. Therefore, Inconel 625 manufactured from Ni-based superalloys, which is extensively used in chemical power plants, can be used in commercial applications after being friction stir welded, because FSW causes an enhancement of its mechanical properties. 


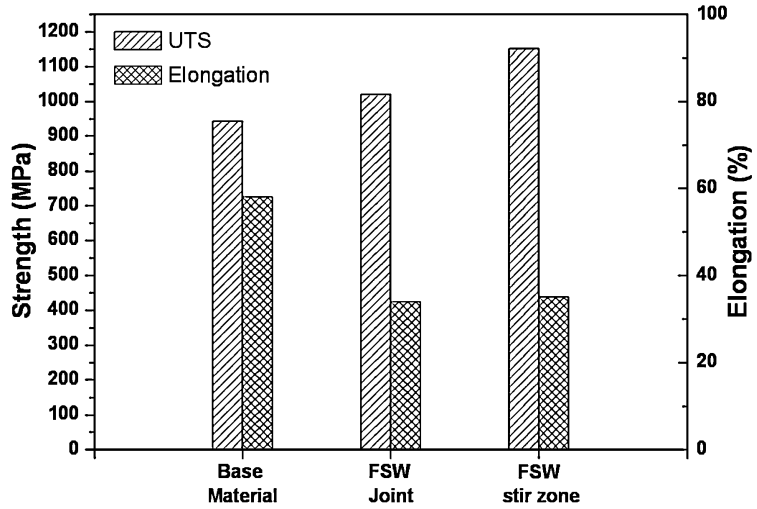

Fig. 7 Base material, weld joint (transverse direction) and stir zone (longitudinal direction) tensile properties of friction-stir-welded specimens.

\section{Acknowledgement}

This work was supported by a Grant-in-Aid for Scientific Research (A) from the Japan Society for the Promotion of Science (JSPS).

\section{REFERENCES}

1) C. T. Sims, N. S. Stoloff and W. C. Hagel: Superalloys II, (WileyInterscience, New York, 1987).

2) V. Shankar, K. B. S. Rao and S. L. Mannan: J. Nucl. Mater. 288 (2001) 222-232.

3) M. Sundararaman, L. Kumar, G. E. Prasad, P. Mukhopadhyay and S. Banerjee: Metall. Mater. Trans. A 30 (1999) 41-52.

4) J. D. Kim, C. J. Kim and C. M. Chung: J. Mater. Process. Tech. 114 (2001) 51-56.

5) M. B. Henderson, D. Arrel, R. Larsson, M. Heobel and G. Marchant: Sci. Tech. Weld. Join. 9 (2004) 13-21.

6) C. J. Dawes and W. M. Thomas: Weld. J. 75 (1996) 41-45.

7) R. S. Mishra and Z. Y. Ma: Mater. Sci. Eng. R 50 (2005) 1-78.

8) J. Altenkirch, A. Steuwer, M. Peel, D. G. Richards and P. J. Withers: Mater. Sci. Eng. A 488 (2008) 16-24.

9) A. Simar, Y. Bréchet, B. de Meester, A. Denquin and T. Pardoen: Mater. Sci. Eng. A 486 (2008) 85-95.

10) R. P. Dobriyal, B. K. Dhindaw, S. Muthukumaran and S. K. Mukherjee: Mater. Sci. Eng. A 477 (2008) 243-249.

11) F. Ye, H. Fujii, T. Tsumura and K. Nakata: J. Mater. Sci. 41 (2006) 5376-5379.

12) K. H. Song, H. Fujii and K. Nakata: Mater. Trans. 50 (2009) 832-836.

13) J. M. Howe: Interfaces in Materials, (Wiley-Interscience, 1997).

14) F. J. Humphreys and M. Hatherly: Recrystallization and Related Annealing Phenomena, 2nd ed., (Elsevier, Oxford, UK, 2004). 